DE GRUYTER
OPEN

\title{
USING DIFFERENT MAPPING FUNCTION IN GPS PROCESSING FOR REMOTE SENSING THE ATMOSPHERE
}

\author{
S. Nistor ${ }^{\text {a, } * \text {, A.S. Buda }}{ }^{\text {a }}$ \\ ${ }^{a}$ University of Oradea, Faculty of Civil Engineering, Cadastre and Architecture, Department Cadastre-Architecture, Romania
}

Received: 10.09.2015 / Accepted: 10.10.2015 / Revised: 18.11.2015 / Available online: 15.12.2015

DOI: 10.1515/jaes-2015-0024

KEY WORDS: GPS, ionosphere, water vapor, zenith tropospheric delays

\begin{abstract}
:
Due to development of GPS technology and by using the combination LC of L1 and L2 frequency the first order effect of the ionosphere tends to be canceled. Thus the main source of errors in the atmosphere which causes the delay in GPS signal is the neutral part of the atmosphere, usually referred to tropospheric delay. In general, the delay is computed at the zenith direction and it is referred to zenith tropospheric delay. The zenith tropospheric delay consist of two parts: zenith hydrostatic delay and zenith wet delay. The zenith hydrostatic delay can be very well modeled which accounts for nearly $90 \%$ to $100 \%$ of the atmospheric delay. The zenith wet delay is due to the water vapor and represents the "harder" part that need to be modeled caused by "unmixed" condition of the wet atmosphere. The influence of the zenith wet delay is around $0-40 \mathrm{~cm}$. The aim of the article is to present the results obtain on the network of three station which were spread around the Oradea city using different types of mapping functions. The mapping functions are: global pressure and temperature - GPT2 and Vienna mapping function - VMF1. For the vertical studies to obtain the highest accuracy, the recommended mapping function is VMF1.
\end{abstract}

\section{INTRODUCTION}

Since the inception of space geodesy, the tropospheric delay plays an important role of the signals propagation when is passing through the atmosphere which affects the geodetic estimations of coordinates of points on the surface of the Earth. The amount of precipitable water vapor $(\mathrm{PW})$ contained in the neutral atmosphere can be inferred from the propagation delay of Global Positioning System (GPS) signals passing through the troposphere. For many years, geodesists have treated such delays as nuisance parameters to be removed in the process of estimating station coordinates (Tregoning et al. 1998).

Troposphere delay modeling is one of the main error sources in the analysis of space geodetic techniques operating at microwave frequencies, such as global navigation satellite systems (GNSS), very long baseline interferometry (VLBI), or Doppler orbitography and radiopositioning integrated by satellite (DORIS) (Nilsson et al. 2013).

\footnotetext{
* Corresponding author. e-mail: sonistor@uoradea.ro
}

The neutral atmosphere, called troposphere, is the lowest part of the earth's atmosphere up to about $80 \mathrm{~km}$ altitude. The neutral atmosphere consists of a combination of several gases. The signal propagation on this layer depends on the temperature, the pressure and the water vapor (Katsougiannopoulos et al. 2006).

The ability to remotely sense the atmosphere using geodetic techniques has dramatically improved over the past decade, primarily as a result of advances in satelliteborne technologies, large-scale and dense geodetic Global Navigation Satellite System (GNSS) networks, new dedicated space missions and developments of new algorithms and innovative methodologies ( $\mathrm{Yu}$ et al. 2014).

Space-geodetic and remote sensing applications suffer from the fact that electromagnetic waves are delayed and bended when they propagate through the Earth's atmosphere, an effect known as troposphere refraction (Hobiger, Boehm, and Ichikawa 2012). 
Global Navigation Satellite System (GNSS) was originally designed for positioning and navigation. Amongst other possible applications it can also be used to derive information about the state of the atmosphere, what is now recognized as GNSS meteorology (Bosy et al. 2012).

Recent developments in both ground-based and satellite-borne geospatial infrastructure have opened exciting new opportunities for geodesists to contribute to big issues such as weather, climate, global warming, environment and sustainability (Yu et al. 2014). Radio signals transmitted from the GPS satellites are delayed by the atmosphere before they are received on the ground. The delay due to the presence of water vapor in the troposphere offers an opportunity to observe precipitable water (PW) using ground-based GPS (Liou, Huang, and Teng 2014).

The dynamics of WV have a strong influence on weather and climate due to the large energy transfers in the hydrological processes. This is particularly so during the formation and life cycle of severe mesoscale convective storm and precipitation systems. Contrary to its importance, WV remains poorly understood and inadequately measured both spatially and temporally, especially in the southern hemisphere, where meteorological data are sparse (Bosy et al. 2012).

The possibility of using GNSS technology for remote sensing the atmospheric water vapor results from the development of "deterministic" least-square and Kalman filtering technique, where the effect created by zenith tropospheric delay that influence the GNSS receiver results from the recorded observation (Bevis et al. 1994). The basic idea is to calculate the tropospheric delay from GPS pseudoranges when station coordinates with high accuracy is known (Katsougiannopoulos et al. 2006).

Ground-based GPS meteorology was introduced by (Bevis et al. 1994). The technique consists of using the tropospheric products estimated from permanent ground-based GPS receivers for Numerical Weather Prediction (NWP). This requires a close collaboration between geodetic and meteorological communities since GPS data are usually observed and processed and the tropospheric products assimilated into NWP models (Dousa and Bennitt 2012).

Over more than a decade, such collaboration has been developed in Europe, namely within the former projects WAVEFRONT, MAGIC, COST-716 and TOUGH. During 2004-2009, the EUMETNET Economic Interest Group (EIG) Global Navigation Satellite System (GNSS) Water Vapour Programme (E-GVAP) was responsible for the coordination of near real time GNSS Zenith Total Delay (Dousa and Bennitt 2012).
Recent research has shown that the estimates of the wet tropospheric delay from very long baseline interferometry (VLBI) and GPS observations agree closely with estimates from radiosonde launches and microwave radiometer (MWR) measurements (Duan et al. 1996)(Van Baelen, Aubagnac, and Dabas 2005)(Kuo et al. 2005)(Wang, Zhang, and Dai 2005). It has been demonstrated through much research that GPS observations allowed us to estimate atmospheric PWV with an accuracy of $1.5 \mathrm{~mm}$ and temporal resolution of about $30 \mathrm{~min}$ under all-weather condition (Ohtani and Naito 2000).

\section{MATERIALS AND METHODS}

With the development of the continuously operating geodetic GPS networks, the data provided by them, can be used in different areas of geodesy, hence the possibility of remote sensing the atmosphere, by determining the zenith wet delay (ZWD) and precipitable water vapour (PWV). This can be obtain by using the concept of "deterministic" least-square technique and Kalman filtering. By using this technique and continuous operating GPS system we are able determine the ZWD with less than $10 \mathrm{~mm}$ of long-term bias in equivalent excess pathlenghts and less than 10 $\mathrm{mm}$ (rms) of random noise (Bevis et al. 1994).

The difference between the true electrical path length and the assumed straight line of the GPS signal that travels from the satellite to the receiver throughout the earth atmosphere bears the name of "atmospheric delay". The electrical path of the signal it's "suffers" a delay and its path changes from a straight line to a curved one. Depending on the meteorological condition and the location of the GPS receiver, the atmospheric delay varies from about 6 to 8 nanosecunds or 10-12 cycles of phase at L1-band or 190 to $240 \mathrm{~cm}$. For the computation of the total zenith delay, the atmospheric delay is broken into two components: dry or hydrostatic delay - ZHD and wet delay - ZWD. So, the zenith tropospheric delay is:

$$
Z T D=Z H D+Z W D=10^{-6} \int_{H}^{\infty} N(s) d s
$$

where $d s$ has units of length in the zenith, $H$ is the surface height and $N(s)$ is the refractivity of air given parts per million (ppm):

$$
\begin{aligned}
N=k_{1}\left(\frac{P_{d}}{T}\right) Z_{d}^{-1} & +k_{2}\left(\frac{e}{T}\right) Z_{\omega}^{-1} \\
& +k_{3}\left(\frac{e}{T^{2}}\right) Z_{\omega}^{-1}
\end{aligned}
$$


Where $P_{d}$ is the the dry air pressure, $T$ is the air temperature in $(\mathrm{K}) e$ is the partial pressure of water vapour (hPA) $Z_{d}$ and $Z_{\omega}$ are the dry air and water vapour compressibility factors, that consider the departure of air from an ideal gas.

In the dry component - ZHD - it is assumed the mean molar mass is equal to the mean molar mass of only the "dry" components excluding the water vapor. If it is assumed that the atmosphere is in is in hydrostatic equilibrium, the zenith dry delay is very well modelled - with an RMS of approximately $0.5 \mathrm{~mm}$. The hydrostatic part is describe by:

$$
Z H D=10^{-6} k_{1} \int \frac{P_{d}}{T} Z_{d}^{-1} d s
$$

The wet component - ZWD is due to the water vapor, and includes a correction for the "dry mean molar mass". Due to the fact that the water vapor is present in the form of water drops which causes the "unmixed" condition of the troposphere, the wet delay estimation is very inaccurate and can have RMS errors of several centimeters. The wet part is describe by:

$$
\begin{aligned}
Z W D=10^{-6} k_{2} \int & \left(\frac{e}{T}\right) Z_{\omega}^{-1} d s \\
& +10^{-6} k_{3} \int\left(\frac{e}{T^{2}}\right) Z_{\omega}^{-1} d s
\end{aligned}
$$

The relationship between zenith wet delay - ZWD and to water wapour - PW is given by:

$$
P W=\Pi * Z W D
$$

where: ZWD is given in units of length and the dimensionless constant of proportionality $\Pi$ is:

$$
\Pi=\frac{10^{6}}{\rho R_{v}\left[\left(k_{3} / T_{m}\right)+k_{2}^{\prime}\right]}
$$

where $\rho$ is the density of liquid water, $R_{v}$ is the specific gas constant for water vapour, and $T_{m}$ is a weighted mean temperature of the atmosphere; $T_{m}$ is defined as:

$$
T_{m}=\frac{\int\left(\frac{P_{v}}{T}\right) d z}{\int\left(\frac{P_{v}}{T^{2}}\right) d z}
$$

Where

$$
k_{2}^{\prime}=k_{2}-m k_{1}
$$

And $m$ is $M_{v} / M_{d}$ which represents the ratio of the molar masses of water vapour and dry air; $k_{2}$ an $k_{1}$ represents the physical constants that are used is atmospheric refractivity, $P_{v}$ is the partial pressure of water vapour and $T$ is the absolute temperature.

\section{RESULTS}

In our experiment we have used three station around the city of Oradea from which one station close to the Fast River. The main purpose was to determine the precipitable water vapor and zenith hydrostatic delay. For this reasons we have used Gamit-Globk (Herring, King, and McClusky 2008) which is a GPS software based on the principle that uses relative positioning. To determine this parameters, we can use both VLBI technique (S Nistor and Buda 2015) and PPP technique (Sorin Nistor and Buda 2015).

Due to the fact that we didn't have in situ meteorological data, for the analysis we have used the GMF - global mapping function and the apriori pressure and temperature was from the GPT2 model developed by (Lagler et al. 2013) and Vienna Mapping Function VMF1 (Boehm, Werl, and Schuh 2006).

In the first part of the analysis we have estimated the precipitable water vapor using the GPT2 model. The results are presented in figure 1 . 


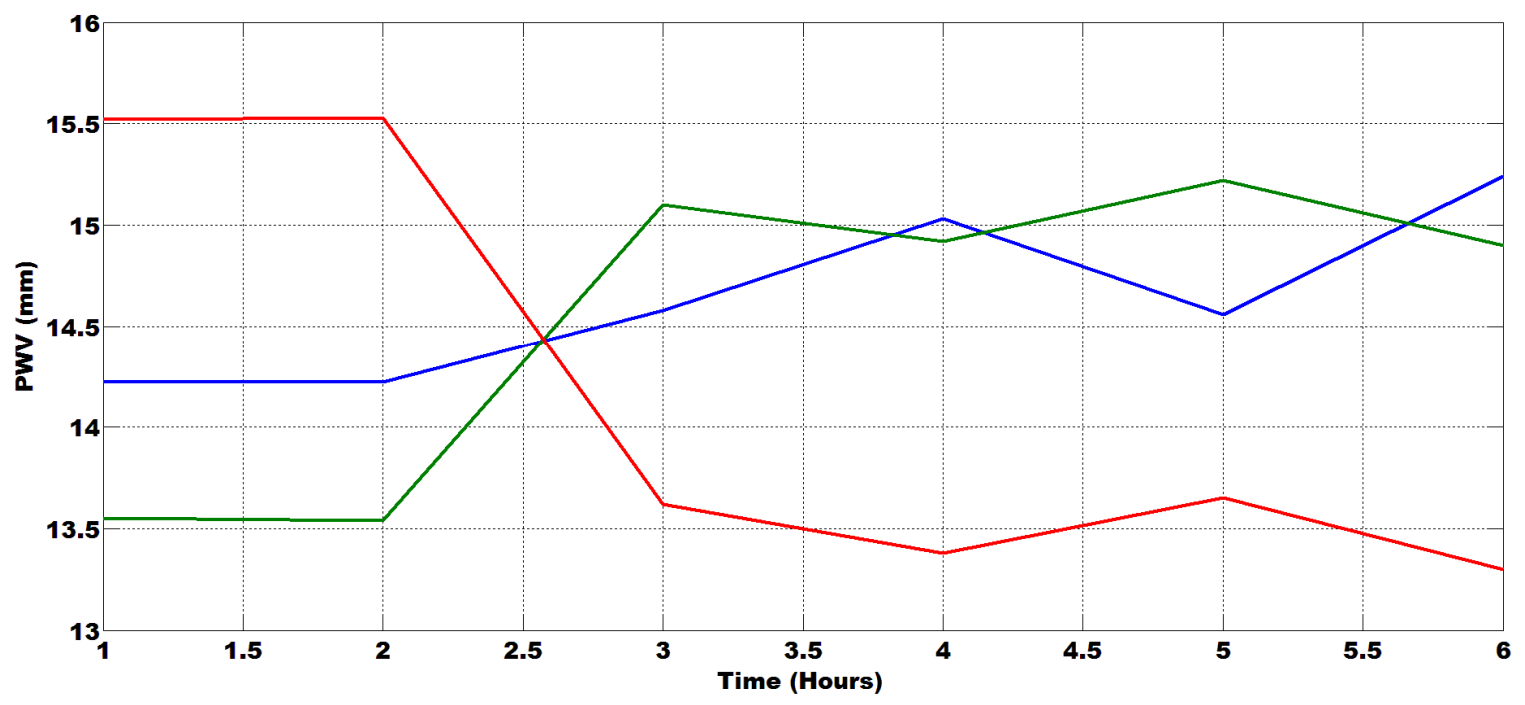

Figure 1. Determination of PWV using GPT 2

The blue line from the plot represents the data from the permanent station Oradea, the green line represents the receiver near to the park and the red line represents the data from the receiver near to the Fast River. Analyzing the results from the plot we can observe that although the receiver near to the river presents the highest value only for 2.5 hours the rest of the time the highest values of precipitable water vapor were from the receiver near to the park and Oradea permanent station.
Using the GPT2 model we have estimated the zenith hydrostatic delay. The pressure and temperature are from the defined model incorporated in GPT2. The most appropriate representation of zenith delay variation is accomplished with a new zenith delay parameter estimated at every 2 hours using the piecewise-linear function - PWL. The results are presented in figure 2 .

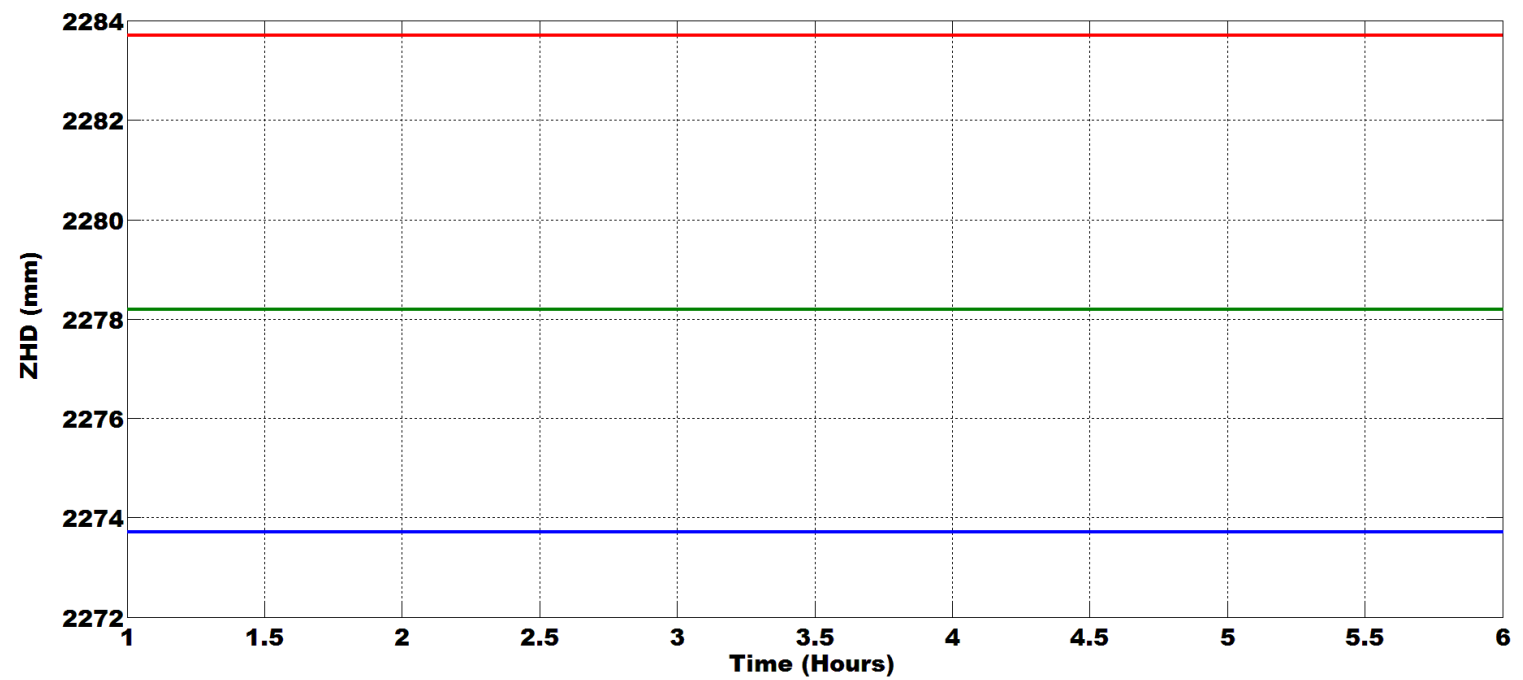

Figure 2. Determination of ZHD using GPT 2 
The blue line from the plot represents the data from the permanent station Oradea, the green line represents the receiver near to the park and the red line represents the data from the receiver near to the Fast River. From the plot we can observe that the highest value was from the data collected from station near to the Fast River and the lowest value was from permanent station Oradea. In this case the highest value was for the station near to the river.

After this determination we have used the VMF1 model to determine the precipitable water vapor (figure 3 ).

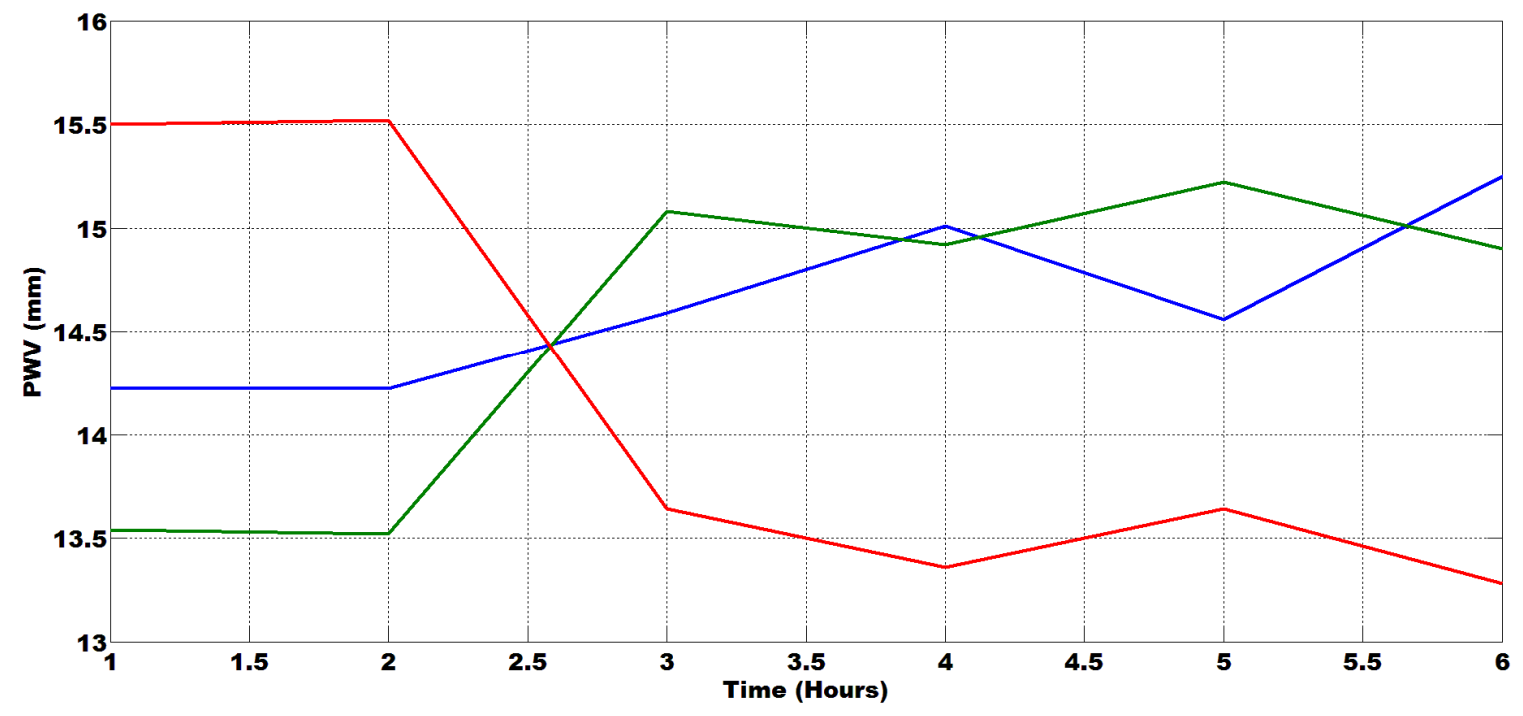

Figure 3. Determination of PWV using VMF1

The blue line from the plot represents the data from the permanent station Oradea, the green line represents the receiver near to the park and the red line represents the data from the receiver near to the Fast River. From the plot we can observe that the highest value were from the data collected from station near to the Fast River and the lowest value was from permanent station Oradea (figure 4).

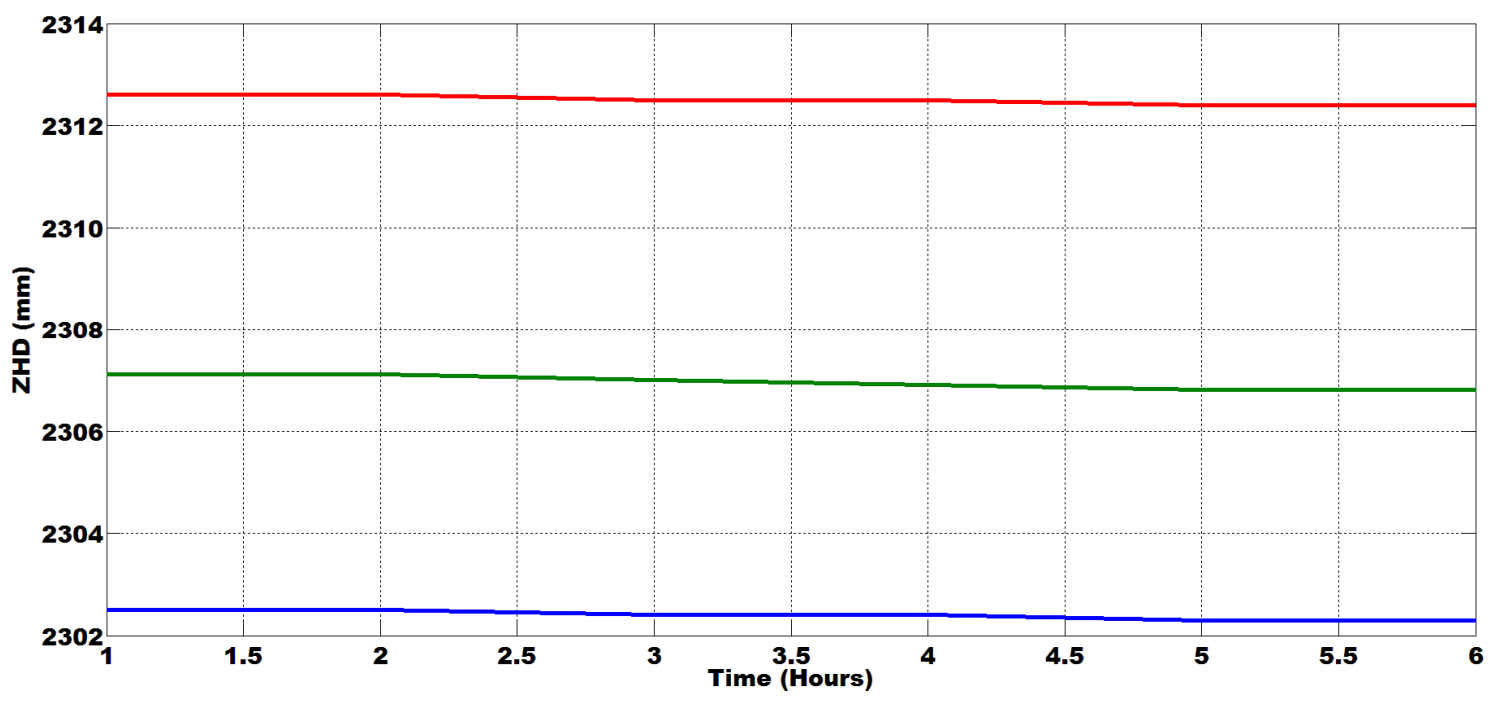

Figure 4. Determination of ZHD using VMF1 
The blue line from the plot represents the data from the permanent station Oradea, the green line represents the receiver near to the park and the red line represents the data from the receiver near to the Fast River. From the plot we can observe that the highest value was from the data collected from station near to the Fast River and the lowest value was from permanent station Oradea. The data for the entire period of six hours "suffers" a small variation form the beginning to end when using the VMF1 model.
To be able to investigate the dependence of the precipitable water vapor and the zenith hydrostatic delay we have overlap the two different mapping function and to test the sensitivity of the PWV and ZHD retrievals depending on the mapping functions. In the computation part we have used precise orbit available from IGS and we didn't recompute the orbits. The results for estimating the precipitable water vapor using both GPT2 and VMF1 models are presented in figure 5.

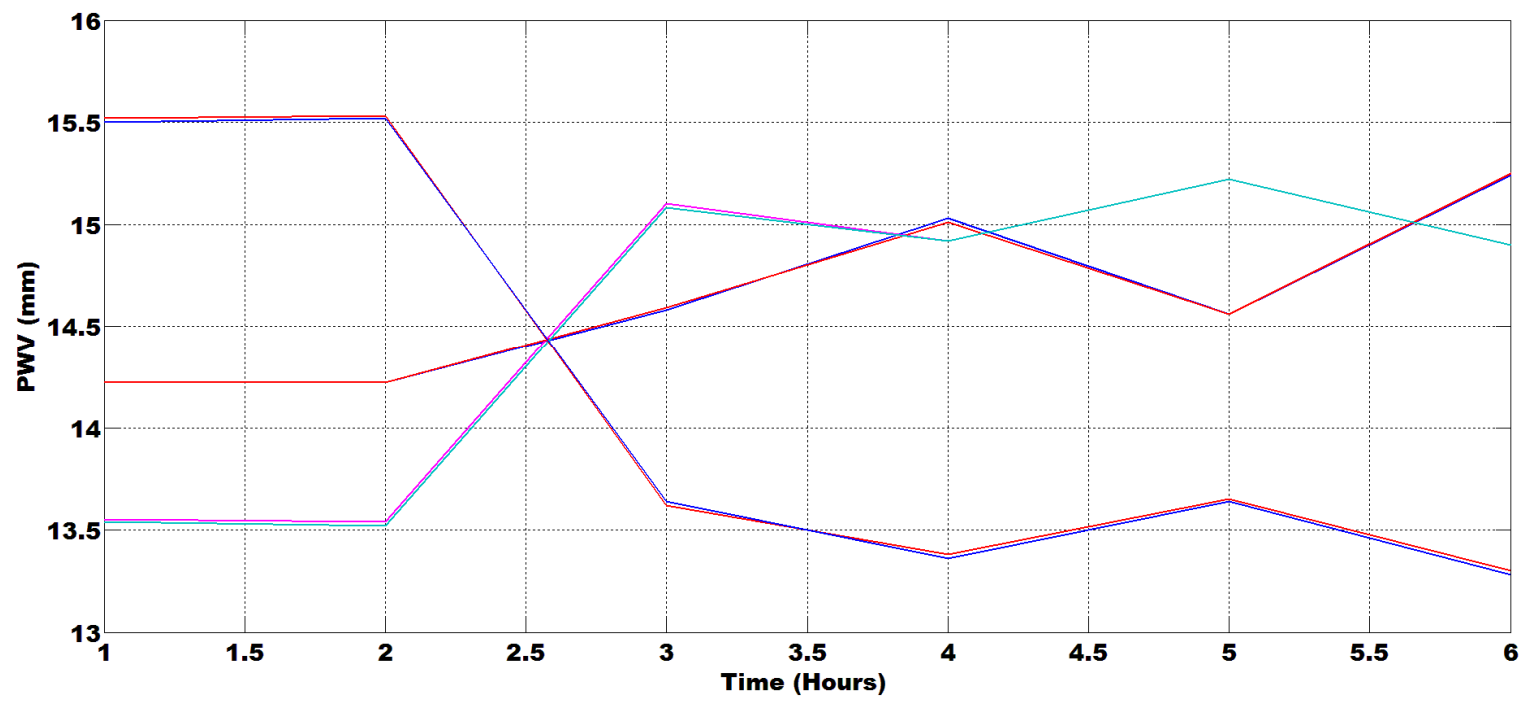

Figure 5. Determination of PWV using GPT2 and VMF1

We can observe that the results are very similar and most of the time the results by using both models overlap for the entire period. The largest variation was for the station near to the river which was around $0.3 \mathrm{~mm}$.
To test the sensitivity of the two models upon the zenith hydrostatic delay we have overlap the results for the GPS2 and VMF1 results which are presented in figure 6.

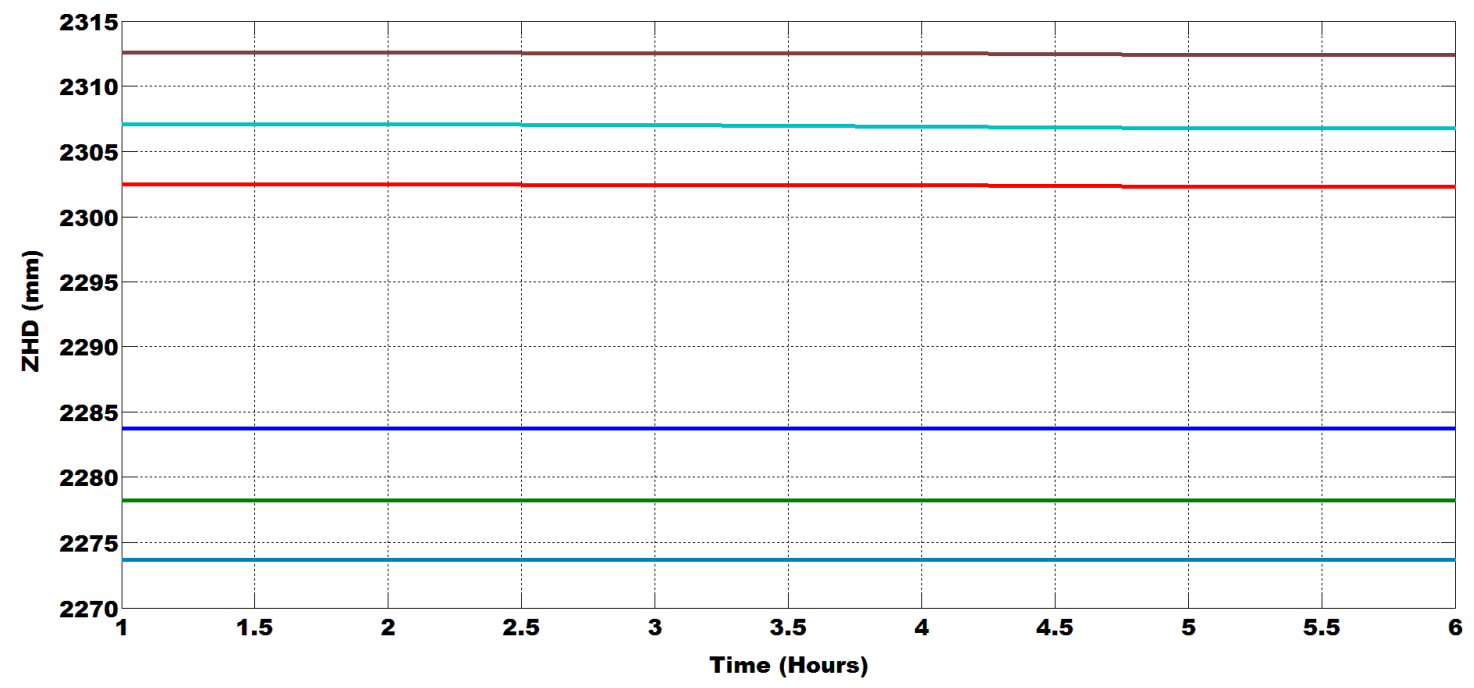

Figure 6. Determination of ZHD using GPT2 and VMF1 
What is interesting between this two model, is that in terms of precipitable water vapor there is not a noticeable difference - less than 1 millimeter for all the three stations. In contradiction with the precipitable water vapor, the zenith hydrostatic delays present large differences for all three stations - around $30 \mathrm{~mm}$.

\section{CONCLUSIONS}

The estimation of ionospheric and tropospheric delays play a crucial factor in high precision position even if the position is determined by relative technique or by precise point positioning.

The paper is presenting an overview of the GPS atmospheric remote sensing with the focus on the influence of the troposphere on the GPS signals using different models - GPT2 and VMF1 - for determining the zenith hydrostatic delay and precipitable water vapor. To obtain the precipitable water vapor the mapping function was used to convert the values from the zenith wet delay. The results present the fact that in terms of precipitable water vapor the difference are not noticeable - less than $1 \mathrm{~mm}$, but in terms of zenith hydrostatic delay the difference is around $30 \mathrm{~mm}$. The recommendation for the determination of elevation with high precision is to use the VMF1 model.

\section{REFERENCE}

Bevis, Michael, Steven Businger, Steven Chiswell, Thomas A Herring, Richard A Anthes, Christian Rocken, and Randolph H Ware. 1994. "GPS Meteorology: Mapping Zenith Wet Delays onto Precipitable Water." Journal of Applied Meteorology 33 (3): 379-86.

Boehm, Johannes, Birgit Werl, and Harald Schuh. 2006. "Troposphere Mapping Functions for GPS and Very Long Baseline Interferometry from European Centre for MediumRange Weather Forecasts Operational Analysis Data." Journal of Geophysical Research 111 (B2): B02406. doi:10.1029/2005JB003629.

Bosy, J, J Kaplon, W Rohm, J Sierny, and T Hadas. 2012. "Near Real-Time Estimation of Water Vapour in the Troposphere Using Ground GNSS and the Meteorological Data." In Annales Geophysicae, 30:1379-91. Copernicus $\mathrm{GmbH}$.

Dousa, Jan, and Gemma V. Bennitt. 2012. "Estimation and Evaluation of Hourly Updated Global GPS Zenith Total Delays over Ten Months.” GPS Solutions 17 (4): 453-64. doi:10.1007/s10291-012-0291-7.

Duan, Jingping, Michael Bevis, Peng Fang, Yehuda Bock, Steven Chiswell, Steven Businger, Christian Rocken, Frederick Solheim, Terasa van Hove, and Randolph Ware.
1996. "GPS Meteorology: Direct Estimation of the Absolute Value of Precipitable Water." Journal of Applied Meteorology 35 (6): 830-38.

Herring, T A, R W King, and S C McClusky. 2008. "Introduction to Gamit/Globk." Massachusetts Institute of Technology, Cambridge.

Hobiger, T, J Boehm, and R Ichikawa. 2012. "Troposphere Delay Modeling-Status Quo and Future Trends.” In AGU Fall Meeting Abstracts, 1:5.

Katsougiannopoulos, S, C Pikridas, D Rossikopoulos, I Ifadis, and A Fotiou. 2006. "Tropospheric Refraction Estimation Using Various Models, Radiosonde Measurements and Permanent GPS Data." PS5. 4-GNSS Processing and Applications, 15.

Kuo, Y-H, W S Schreiner, J Wang, D L Rossiter, and Y Zhang. 2005. "Comparison of GPS Radio Occultation Soundings with Radiosondes.” Geophysical Research Letters 32 (5). Wiley Online Library.

Lagler, Klemens, Michael Schindelegger, Johannes Böhm, Hana Krásná, and Tobias Nilsson. 2013. "GPT2: Empirical Slant Delay Model for Radio Space Geodetic Techniques." Geophysical Research Letters 40 (6). Wiley Online Library: 1069-73.

Liou, Yuei-An, Cheng-Yung Huang, and Yu-Tun Teng. 2014. "Precipitable Water Observed by Ground-Based GPS Receivers and Microwave Radiometry." Earth, Planets and Space 52 (6): 445-50. doi:10.1186/BF03352256.

Nilsson, Tobias, Johannes Böhm, DudyD. Wijaya, Ana Tresch, Vahab Nafisi, and Harald Schuh. 2013. "Path Delays in the Neutral Atmosphere." In Atmospheric Effects in Space Geodesy $S E$ - 3, edited by Johannes Böhm and Harald Schuh, 73-136. Springer Atmospheric Sciences. Springer Berlin Heidelberg. doi:10.1007/978-3-642-36932-2_3.

Nistor, S, and A S Buda. 2015. "Scheduling And Simulation Of VLBI Measuremets For The Determination Of Earth Orientation Parameters." Journal of Applied Engineering Sciences 5 (1): 61-68.

Nistor, Sorin, and Aurelian Stelian Buda. 2015. “Ambiguity Resolution in Precise Point Positioning Technique: A Case Study.” Journal of Applied Engineering Science.

Ohtani, Ryu, and Isao Naito. 2000. "Comparisons of GPSderived Precipitable Water Vapors with Radiosonde Observations in Japan." Journal of Geophysical Research: Atmospheres (1984-2012) 105 (D22). Wiley Online Library: 26917-29.

Tregoning, Paul, Reinout Boers, Denis O'Brien, and Martin Hendy. 1998. "Accuracy of Absolute Precipitable Water Vapor Estimates from GPS Observations.” Journal of Geophysical 
Research 103 (D22): 28701. doi:10.1029/98JD02516.

Van Baelen, Joël, Jean-Pierre Aubagnac, and Alain Dabas. 2005. "Comparison of near-Real Time Estimates of Integrated Water Vapor Derived with GPS, Radiosondes, and Microwave Radiometer." Journal of Atmospheric and Oceanic Technology 22 (2): 201-10.

Wang, Junhong, Liangying Zhang, and Aiguo Dai. 2005. "Global Estimates of Water-vapor-weighted Mean Temperature of the Atmosphere for GPS Applications." Journal of Geophysical Research: Atmospheres (1984-2012) 110 (D21). Wiley Online Library.

Yu, Kegen, Chris Rizos, Derek Burrage, Andrew G Dempster, Kefei Zhang, and Markus Markgraf. 2014. "An Overview of GNSS Remote Sensing." EURASIP Journal on Advances in Signal Processing 2014 (1): 134. doi:10.1186/1687-6180-2014-134. 